\title{
Treatment of Morbihan disease
}

\section{Joo Hyoung Kim}

Department of Plastic and Reconstructive Surgery, Pusan National University School of Medicine and Biomedical Research Institute, Pusan National University Hospital, Busan, Korea
Morbihan disease (MD) is a rare condition that involves rosaceous lymphedema or erythematous lymphedema of the middle and upper thirds of the face. It typically affects the periorbital region, forehead, glabella, nose, and cheeks. The etiology of MD remains unclear, and its diagnosis is challenging. MD often tends to be unresponsive to therapies commonly used to treat rosacea, including corticosteroids, isotretinoin, and antibiotics. Surgical treatments have therefore been attempted, but most cases showed unsatisfactory responses. These problems could have resulted from an incorrect recognition and interpretation of the pathophysiology of $\mathrm{MD}$ and inaccurate planning of the operation, resulting in recurrence or exacerbation of edema.

Abbreviations: MD, Morbihan disease; LVA, lymphaticovenular anastomosis.

Keywords: Edema / Eyelids / Lymphedema

\section{INTRODUCTION}

Morbihan disease (MD) is a rare disease, with an unclear place in the nosography. MD was first described in 1957 by the French dermatologist Degos, and is characterized by rosaceous lymphedema or erythematous edema of the middle and upper thirds of the face [1]. It typically affects the periorbital region, glabella, nose, and cheeks. In MD, edema and erythema are not usually associated with pain or pruritis, but they can cause significant changes in the periorbital contour, leading to visual impairment and cosmetic disfigurement. Although MD is generally considered to be a chronic form of rosacea, it may exist in the absence of other features of rosacea, and thus may represent a separate disease process. The difficulty of diagnosing MD is that there are many similar diseases, e.g., myxomas, lympho-

Correspondence: Joo Hyoung Kim

Department of Plastic and Reconstructive Surgery, Pusan National University

School of Medicine and Biomedical Research Institute, Pusan National University

Hospital, 179 Gudeok-ro, Seo-gu, Busan 49241, Korea

E-mail: medic144@hanmail.net

This work was supported by clinical research grant from Pusan National University Hospital in 2021.

Received May 10, 2021 / Revised May 10, 2021 / Accepted May 18, 2021 mas, granulomas, and rhinophymas, which causes confusion [2-5]. In addition, there is no standard treatment modality and regimen. In this study, we present an overview of the pathophysiology, diagnosis, and treatment of MD.

\section{CLINICAL FEATURES}

$\mathrm{MD}$ is characterized by a chronic and recurrent pattern of erythema and symmetrical non-pitting facial edema, mainly in the middle and upper thirds of the face (cheek, nose, glabella, periorbital region, and forehead) with accentuation of the periorbital region (Fig. 1). The onset of MD is usually slow, with intermittent reversible swelling eventually becoming permanent swelling and thickening of the skin. Other features of rosacea may be present, such as telangiectasia, papules, and pustules [6]. This process can lead to distortion of the facial contour and vision impairment due to narrowed visual field, and can cause psychosocial stress.

\section{PATHOPHYSIOLOGY}

The pathogenesis of MD remains uncertain. In MD, lymphede- 


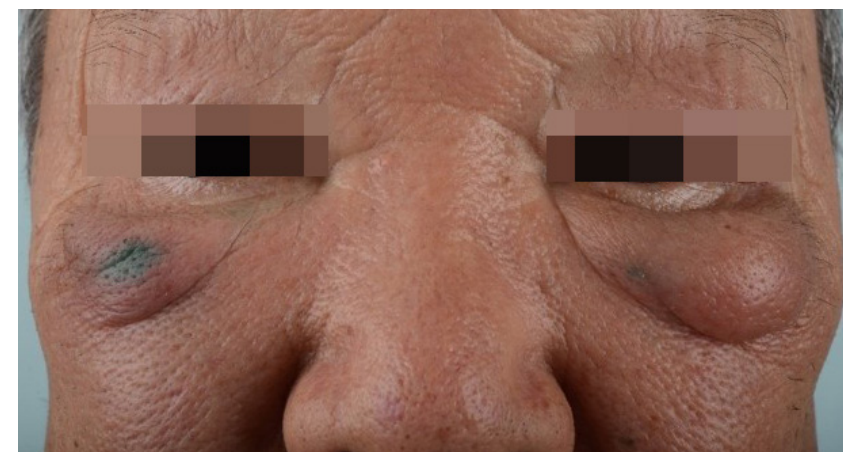

Fig. 1. A 70-year-old Morbihan disease patient. Chronic and nonpitting edema at periorbital region.

ma follows the loss of lymphatic vessel wall integrity and the leakage of intraluminal fluid through the lymphatic vessel wall [7]. The cause is unknown, but possible pathogenic factors have been suggested, such as local dysregulation of lymphatic vessels, lymphatic obstruction by granulomas and histiocytes, and chronic inflammation due to acne, rosacea, or contact dermatitis that destroys supporting connective tissue around dermal lymphatic vessels [8]. Jansen and Plewig [9] reported infiltration of mast cells around the lymphatic collecting vessels, and suspected that mast cells might play an important role in the pathogenesis of MD. However, mast cell infiltration is not a consistent histologic finding in MD. These obscure aspects of the pathophysiology add to the difficulty of diagnosing and treating MD.

\section{DIAGNOSIS}

There are no biochemical or histopathological findings specific to MD. Therefore, for the differential diagnosis, biopsy of the affected tissue is recommended. The histopathologic findings of MD include perivascular dermal edema, lymphohistiocytic infiltration, mast cell infiltration to the periadnexal tissues of the lymph vessels, dilation of lymphatic vessels, non-caseating granulomas, and sebaceous gland hyperplasia [10]. The differential diagnosis for MD includes other granulomatous and inflammatory facial conditions [11]. Diseases to consider include sarcoidosis, orofacial granulomatosis, systemic lupus erythematosus, foreign body granuloma, scleroedema of Buschke, lupus vulgaris, and cutaneous pseudolymphoma. Patch tests can exclude allergic contact dermatitis. Functional evaluation of the facial lymphedema using indocyanine green lymphography is helpful for evaluating lymphatic function and planning lymphatic surgery (Fig. 2) [12].

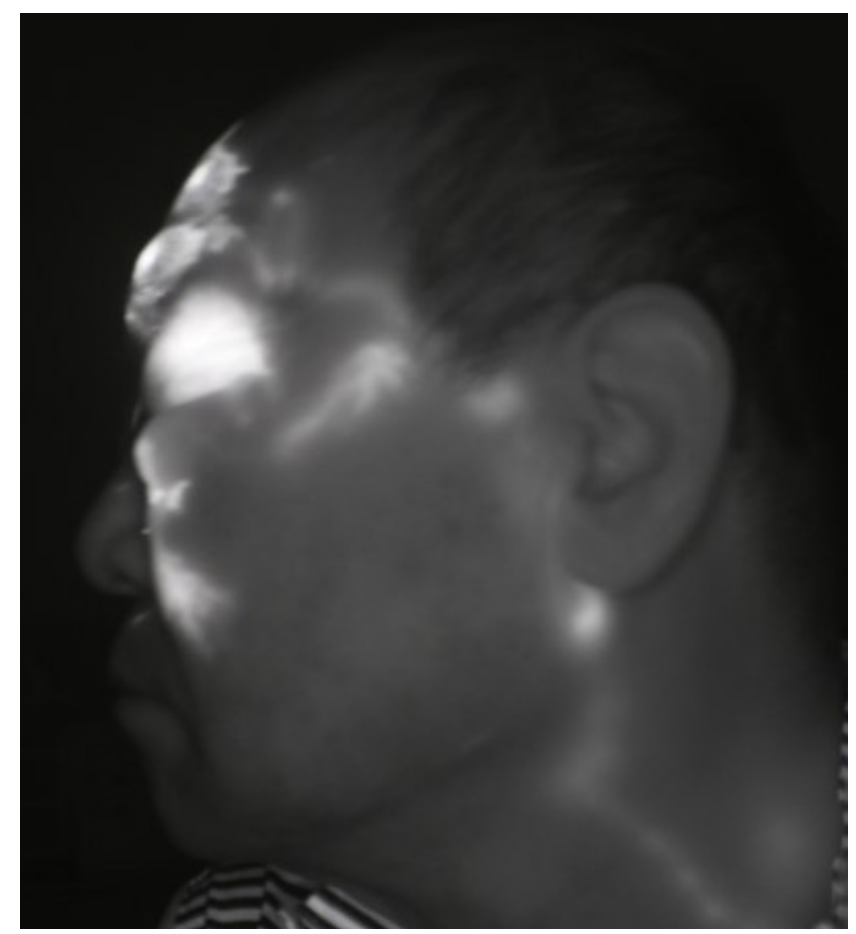

Fig. 2. Indocyanine green lymphography of Morbihan disease patient. A 70-year-old male biopsy proven Morbihan disease patient. Severe dermal backflow noted at periorbital region.

\section{TREATMENT}

The treatment of MD is frequently refractory and difficult. There is no definitive treatment modality and regimen.

Several reports have described medical treatments, including systemic corticosteroids, tetracycline, doxycycline, thalidomide, and isotretinoin, but most cases exhibit a chronic refractory waxing-and-waning course and inadequate treatment response [13]. The antibiotics tetracycline, minocycline, and doxycycline are effective for inflammatory rosacea that can be checked with histopathology, which shows extensive mast cell infiltration [14-16]. Shim et al. [17] reported successful treatment with doxycycline and colchicine over 7 months without recurrence during 14 months of follow-up. If there is an inadequate response to medical treatment, it is possible to attempt surgical treatment, such as eyelid reduction surgery, lymphatic drainage surgery, carbon dioxide laser treatment, and local steroid injections $[18,19]$. Simple excisional surgery is not effective and complete excision is not feasible for aesthetic and functional reasons. Excisional surgery poses a risk of recurrence or even exacerbation of edema. Standard compression therapy for lymphedema is not applicable to MD due to the function of the affected anatomic region. Furthermore, as an important surgical treatment for facial lymphedema after head and neck cancer treatment, lymphaticovenular anastomosis (LVA) is effective 
[20]. Similar to extremity lymphedema, LVA is a curative physiological treatment for facial lymphedema in which a new drainage pathway is made by a lymphatic-vein bypass. Based on this evidence, lymphatic drainage surgery is applicable to the treatment of MD. For lymphatic bypass surgery for the treatment of periorbital edema, drainage can be achieved by anastomosis of a subdermal venule with a lymphatic collecting vessel in the preauricular region [12]. In addition to the lymphatic collecting vessels, there are lymph nodes in the preauricular region that can be shunted to venous drainage using a nodal-venous anastomosis to the facial vein. Both LVA and nodal-venous anastomosis can increase the outflow of lymph drainage from the periorbital region. This type of lymphatic drainage surgery can be performed under local anesthesia. Another advantage of these supermicrosurgical procedures is a lower potential for eyelid malposition than in blepharoplasty or excisional surgery. Another physiological option is vascularized lymph node transfer using a lymph node flap to the preauricular region. However, lymph node transfer for the facial region is too invasive to perform under local anesthesia and not acceptable from an aesthetic standpoint.

\section{CONCLUSION}

The diagnosis and treatment of $\mathrm{MD}$ are challenging. The diagnosis can be made by eliminating possibilities in the differential diagnosis that are similar in terms of clinical and histopathological features. Medical treatment includes antibiotics for inflammatory cases, but mostly yields unsatisfactory results. Surgical treatment options include excisional surgery and functional lymphatic surgery. Considering the psychosocial stress and social/professional impact of MD, efforts must be made to elucidate its pathophysiology in order to develop better treatments in the future.

\section{NOTES}

\section{Conflict of interest}

No potential conflict of interest relevant to this article was reported.

\section{Patient consent}

The patient provided written informed consent for the publication and use of his images.

\section{ORCID}

Joo Hyoung Kim

\section{REFERENCES}

1. Degos R, Civatte J, Beuve-Mery M. Nouveau cas d'oedème érythémateux facial chronique. Bull Soc Fr Dermatol Syph 1973;80:257.

2. Kang JK, Lee JS, Choi JH, Shin MS, Yun BM. Surgical treatment of rhinophyma using an ordinary bur. Arch Craniofac Surg 2020;21:264-7.

3. Jang JW, Kang SY. Evaluation and management of facial granuloma caused by various injection materials. Arch Craniofac Surg 2021;22:26-32.

4. Lee CL, Lee IS, Jung SG. A case of nodal marginal zone B-cell lymphoma of the lower eyelid. Arch Craniofac Surg 2020;21: 249-52.

5. Kim SM, Kim CK, Kim SH, Lee MC, Kim JN, Choi HG, et al. Myxoma arising from the parotid gland. Arch Craniofac Surg 2019;20:186-90.

6. Hu SW, Robinson M, Meehan SA, Cohen DE. Morbihan disease. Dermatol Online J 2012;18:27.

7. Nagasaka T, Koyama T, Matsumura K, Chen KR. Persistent lymphoedema in Morbihan disease: formation of perilymphatic epithelioid cell granulomas as a possible pathogenesis. Clin Exp Dermatol 2008;33:764-7.

8. Wohlrab J, Lueftl M, Marsch WC. Persistent erythema and edema of the midthird and upper aspect of the face (morbus morbihan): evidence of hidden immunologic contact urticaria and impaired lymphatic drainage. J Am Acad Dermatol 2005; 52:595-602.

9. Jansen T, Plewig G. The treatment of rosaceous lymphoedema. Clin Exp Dermatol 1997;22:57.

10. Jungfer B, Jansen T, Przybilla B, Plewig G. Solid persistent facial edema of acne: successful treatment with isotretinoin and ketotifen. Dermatology 1993;187:34-7.

11. Batra M, Bansal C, Tulsyan S. Granulomatous rosacea: unusual presentation as solitary plaque. Dermatol Online J 2011;17:9.

12. Koshima I, Imai H, Yoshida S, Nagamatsu S, Yokota K, Mizuta $\mathrm{H}$, et al. Lymphaticovenular anastomosis for persistent immunosuppressant-related eyelid edema. Int Microsurg J 2018;2:1.

13. Crawford GH, Pelle MT, James WD. Rosacea: I. etiology, pathogenesis, and subtype classification. J Am Acad Dermatol 2004;51:327-41.

14. Fujimoto N, Mitsuru M, Tanaka T. Successful treatment of Morbihan disease with long-term minocycline and its association with mast cell infiltration. Acta Derm Venereol 2015;95: 368-9.

15. Kabuto M, Fujimoto N, Honda S, Tanaka T. Successful treatment with long-term use of minocycline for Morbihan disease showing mast cell infiltration: a second case report. J Dermatol 
2015;42:827-8.

16. Okubo A, Takahashi K, Akasaka T, Amano H. Four cases of Morbihan disease successfully treated with doxycycline. J Dermatol 2017;44:713-6.

17. Shim WH, Jwa SW, Song M, Kim HS, Ko HC, Kim BS, et al. Morbihan disease: a rare variant of rosacea. Korean J Dermatol 2012;50:320-3.

18. Chalasani R, McNab A. Chronic lymphedema of the eyelid: case series. Orbit 2010;29:222-6.

19. Bechara FG, Jansen T, Losch R, Altmeyer P, Hoffmann K. Morbihan's disease: treatment with $\mathrm{CO} 2$ laser blepharoplasty. J Dermatol 2004;31:113-5.

20. Mihara M, Uchida G, Hara H, Hayashi Y, Moriguchi H, Narushima $\mathrm{M}$, et al. Lymphaticovenous anastomosis for facial lymphoedema after multiple courses of therapy for head-andneck cancer. J Plast Reconstr Aesthet Surg 2011;64:1221-5. 